\title{
Study of superficial properties of titanium treated by PIIID
}

\author{
R.C.C. Rangel ${ }^{1, a}$, E.C. Rangel ${ }^{1}$, R.M. Oliveira ${ }^{2}$, M. Ueda ${ }^{2}$, W.H. Schreiner ${ }^{3}$, and N.C. Cruz $^{1}$ \\ ${ }^{1}$ Laboratory of Technological Plasmas, Paulista State University, Av. 3 de Março, 511, 18087-180 Sorocaba, Brazil \\ ${ }^{2}$ National Institute for Space Research, Associated Laboratory of Plasma, Av. dos Astronautas, 1758, 12227-010 \\ São José dos Campos, Brazil \\ ${ }^{3}$ Department of Physics, Federal University of Paraná, P.O. Box 19044, 12227-010 Curitiba, Brazil
}

Received: 15 April 2011 / Received in final form: 18 July 2011 / Accepted: 3 August 2011 Published online: 28 October 2011 - (c) EDP Sciences 2011

\begin{abstract}
Chemical composition and topography of titanium surface are important factors to improve osteointegration. Surfaces with different roughness and chemical composition respond differently when in a biologic environment. In this work, calcium incorporation to $\mathrm{Al}_{2} \mathrm{O}_{3}$ sandblasted titanium surfaces has been achieved by Plasma Immersion Ion Implantation and Deposition (PIIID). Granulated calcium was sublimated by an electron beam at the same time as negative pulses $(5 \mathrm{kV}, 30 \mu \mathrm{s}$ and $400 \mathrm{~Hz})$ were applied to titanium samples immersed in argon DC plasmas. During the ON time of the pulses, positive ions in the plasma were implanted on the surface while between the pulses the surface was covered by a metallic calcium layer. Modified surfaces were characterized before and after soaking the samples in simulated body fluid (SBF), to evaluate the effect of the treatments on the titanium bioactivity. Morphology, composition and chemical structure were evaluated by scanning electron microscopy, energy dispersive and infrared absorption spectroscopies, respectively. Selected sample was also characterized by X-ray photoelectron spectroscopy. The results have shown that the concentrations of calcium and phosphorus, after the immersion in SBF, were larger on the plasma treated titanium samples if compared to the as-received material. Those elements can be present on the surface forming bioactive species such as $\mathrm{CaTiO}_{3}, \mathrm{CaCO}_{3}$ and hydroxyapatite (HA).
\end{abstract}

\section{Introduction}

The loss of a body part causes functional damages, psychological trauma and social disorder. Nowadays, prosthesis and implants are used to solve such problems and to provide better life conditions. Titanium is the most used material in orthopedic and dental implants due to its good mechanical properties, biocompatibility and corrosion resistance. Despite these advantages, titanium is not an ideal biomaterial because it does not present a good bioactivity when in contact with physiological fluids [1]. That is, the formation of hydroxyapatite (the main mineral bone component) does not occur spontaneously on polished pristine titanium surfaces immersed in body solutions $[2,3]$. Owing to that, different approaches to improve Ti bioactivity have been investigated. In this context, ion implantation must be highlighted due to the good results attained with such technique, as recently reviewed by Rautray et al. [4].

In the past few years, plasma immersion ion implantation (PIII) [5] has been consolidated as an important alternative to the experimental and economic drawbacks intrinsically associated to the conventional ion implanta-

\footnotetext{
a e-mail: rita.rangel@gmail.com
}

tion technique. Namely, PIII is cheaper, faster and it is able to modify homogeneously all the surfaces exposed to the plasma without the need of sample manipulation. In this work, the incorporation of calcium on sandblasted titanium surfaces was performed by Plasma Immersion Ion Implantation and Deposition (PIIID). The modified surfaces were investigated before and after immersion for 14 days in simulated body fluid (SBF) [6].

\section{Experimental}

Prior to the treatments, medical grade titanium coupons were sandblasted with $250 \mu \mathrm{m}$ in diameter $\mathrm{Al}_{2} \mathrm{O}_{3}$ spheres. The samples were then cleaned in ultrasonic baths of acetone, water and isopropyl alcohol.

Figure 1 shows the schematic representation of the experimental setup used in the depositions. A complete description of the system is presented elsewhere [7]. Essentially, it is composed of a $60-1$ stainless steel vacuum chamber, containing a small molybdenum crucible where granulated metallic calcium is placed [7]. This crucible, which temperature is monitored by a pyrometer, is heated through the bombardment of electrons emitted by a tantalum filament. The filament current was kept 


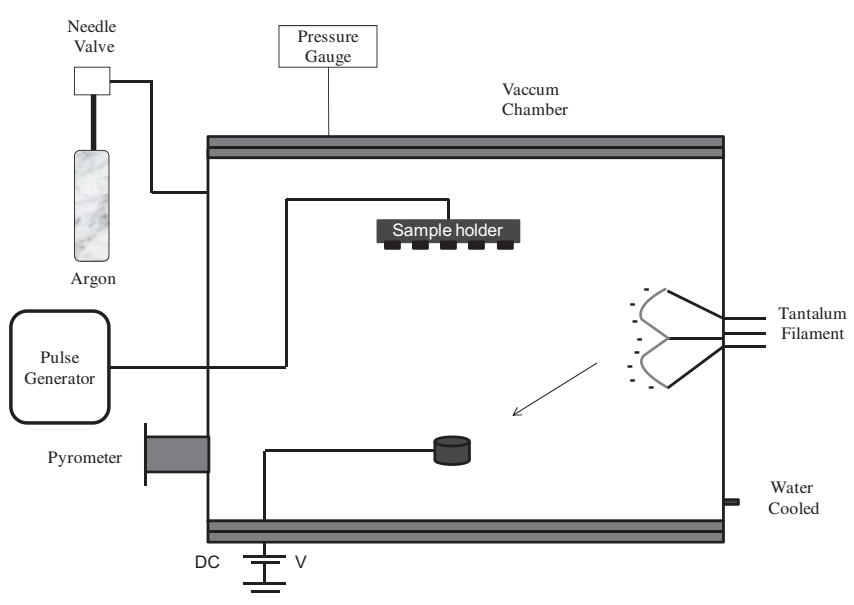

Fig. 1. Experimental apparatus employed for film deposition and treatment.

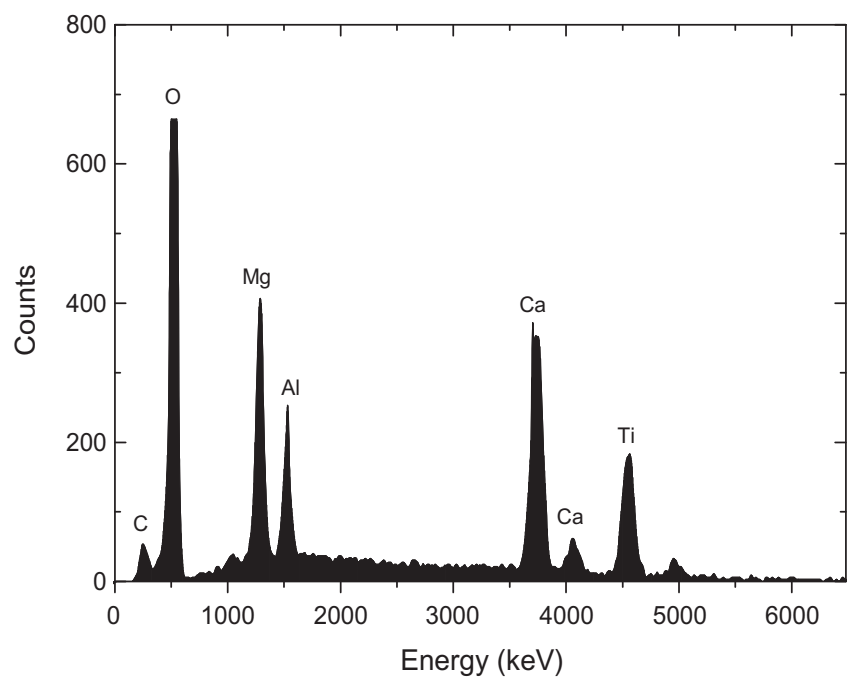

Fig. 2. EDS spectrum of titanium coated by a calciumcontaining film by PIIID.

at about $10 \mathrm{~A}$ by an adjustable transformer. In this reactor, the substrate holder is located at the top of the chamber and the samples are mounted on it facing down. Prior to the treatments the chamber is pumped down to $5.3 \times 10^{-3} \mathrm{~Pa}$ by roots and diffusion pumps. Deposition plasmas were generated in argon and calcium vapor atmosphere $\left(2.1 \times 10^{-1} \mathrm{~Pa}\right)$, through the application of a DC voltage $(120 \mathrm{~V}, 320 \mathrm{~mA})$ between the crucible and the chamber walls, which are water cooled. To enable film deposition upon ion bombardment, the sample holder was biased with high voltage negative pulses $(5 \mathrm{kV}, 400 \mathrm{~Hz})$. The pulse on- and off-time were 0.03 and $2.47 \mathrm{~ms}$, respectively. The treatment has been performed for $1500 \mathrm{~s}$ with the crucible heated up to $600{ }^{\circ} \mathrm{C}$.

After the treatment, a set of samples was sonicated in acetone baths, rinsed in deionized water and then immersed in SBF [6] for 14 days to evaluate the bioactivity of such calcium-coated titanium surfaces.

The morphology of the soaked surfaces was investigated by scanning electron microscopy (SEM) using the

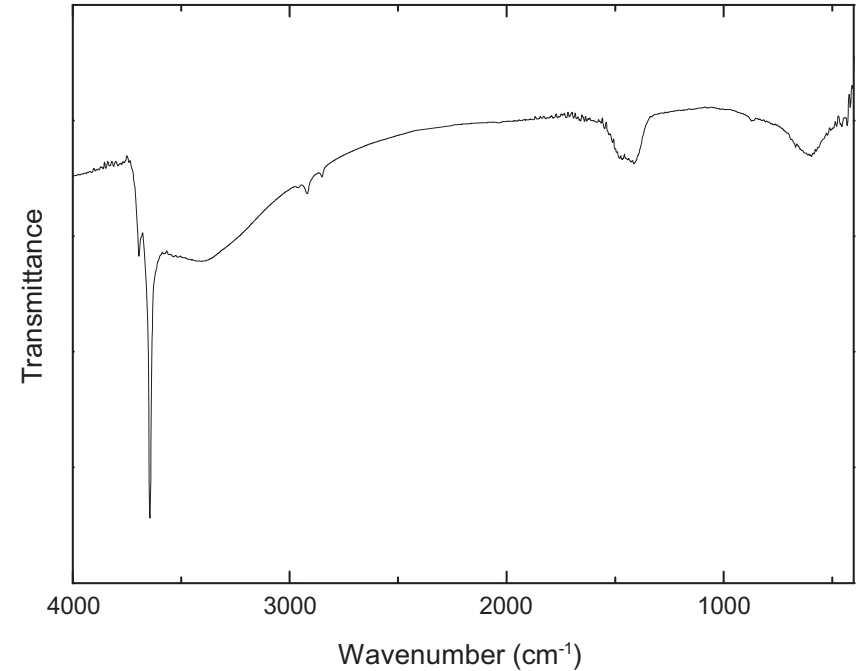

Fig. 3. IR spectrum of titanium coated by a calciumcontaining film by PIIID.

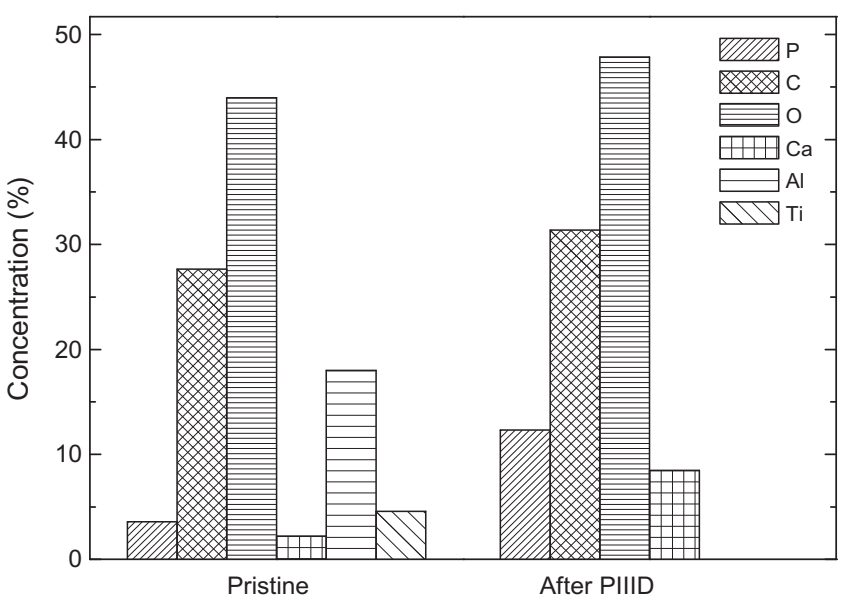

Fig. 4. Atomic concentration determined by XPS of pristine and PIIID treated titanium surfaces after immersion in SBF.

JEOL (JSM-5310) microscope. The beam energy was $20 \mathrm{keV}$ and the images were acquired with the secondary electrons detector. The same instrument was used to evaluate surface composition by energy dispersive X-ray spectroscopy (EDS). The working distance was $25 \mathrm{~mm}$ and the acceleration voltage was $5 \mathrm{kV}$. The magnification was $100 \times$, corresponding to a probed area of $1 \mathrm{~mm}^{2}$. Chemical structure of the films was analyzed by infrared reflectanceabsorbance spectroscopy (IRRAS), using a Jasco FTIR 410 spectrometer and co-adding 128 spectra with a resolution of $4 \mathrm{~cm}^{-1}$. Chemical composition of the soaked surfaces was investigated by X-ray photoelectron spectroscopy (XPS) using a Microtech-ESCA 3000 spectrometer. Experiments were conducted under a base pressure of $2 \times 10^{-8} \mathrm{~Pa}$ using $\mathrm{Mg} \mathrm{K} \alpha$ radiation of about $0.8 \mathrm{eV}$ in resolution. No attempt was made to remove surface contaminants. High resolution spectra were calibrated in energy by the reference carbon $1 s$ peak at $284.6 \mathrm{eV}$ and fitted with Gaussian peaks after subtraction of the Shirley-type background. For the infrared spectroscopy, aluminum-coated 
(a) $\mathrm{Ca} 2 \mathrm{p}$

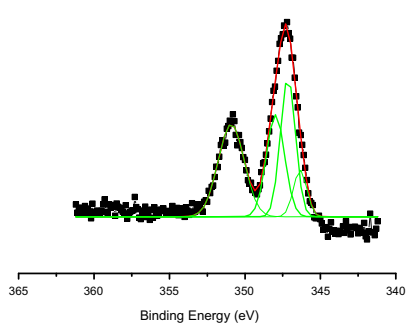

(c) $\mathrm{O} 1 \mathrm{~s}$

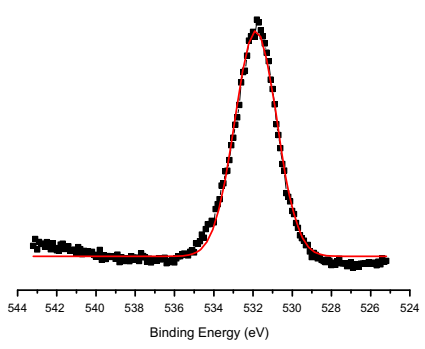

Fig. 5. (Color online) High resolution XPS spectra of Ca, $\mathrm{P}$ and $\mathrm{O}$ on titanium surface coated by a PIIID calciumcontaining film after immersion in SBF.

glass plates were used as substrates. For all the other analysis, sandblasted titanium was employed.

\section{Results and discussion}

Figure 2 shows the EDS spectrum of a modified sample before the immersion in $\mathrm{SBF}$. The presence of $\mathrm{Ca}, \mathrm{Al}, \mathrm{Mg}$, $\mathrm{Ti}, \mathrm{O}$ and $\mathrm{C}$ can be observed. The presence of aluminum may be attributed to traces of the alumina used for sandblasting while oxygen and carbon may result from chemical reactions involving calcium and atmospheric species such as water vapor and carbon dioxide when the surface is exposed to air.

A typical IR spectrum is shown in Figure 3. The absorption band at $3640 \mathrm{~cm}^{-1}$ results from $\mathrm{O}-\mathrm{H}$ stretching while the absorption at $1430 \mathrm{~cm}^{-1}$ is ascribed to $\mathrm{C}=\mathrm{O}$ bonds in calcium carbonate $[8]$.

Figure 4 shows the composition and atomic concentration, obtained by XPS, of surface of pristine and PIIID modified titanium samples after immersion in SBF. Although calcium, phosphorus and oxygen, which are elements present in hydroxyapatite, have been detected in both samples, their concentrations are higher on the treated material. This result is in accordance with previous works that have shown the improvement of the precipitation of calcium phosphate on calcium-containing titanium surfaces when exposed to physiological solutions [2]. The formation of calcium phosphate is accelerated by ionic exchanges of calcium on the surface by species on the simulated body fluid [9].

Figure 5 shows typical high resolution XPS spectra of $\mathrm{Ca} 2 p, \mathrm{P} 2 p$ and $\mathrm{O} 1 s$. As it can be noticed the Ca spectrum is composed by two peaks centered at $347.0 \mathrm{eV}$ $\left(2 p_{3 / 2}\right)$, and $350.8 \mathrm{eV}\left(2 p_{1 / 2}\right)$. The first peak can be (a)

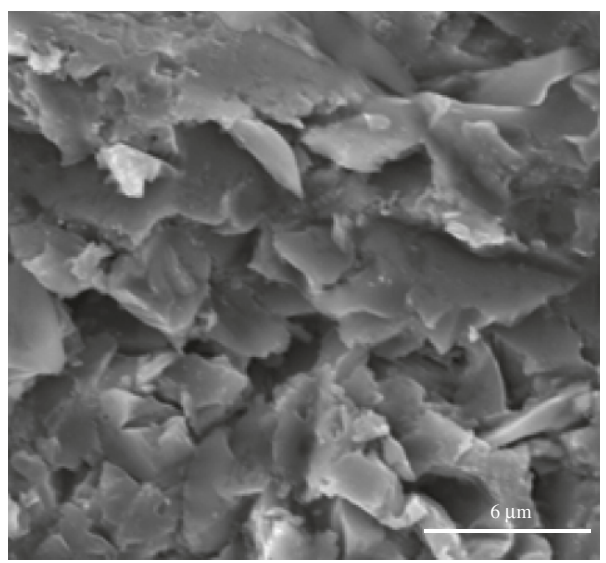

(b)

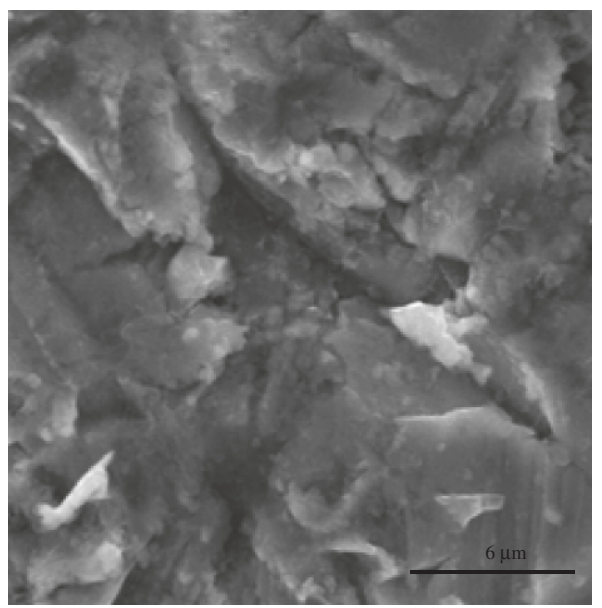

Fig. 6. Images obtained by SEM of the (a) pristine and (b) PIIID-coated titanium surfaces after immersion in SBF.

deconvoluted using three Gaussian curves centered at $346.5,347.0$, and $347.6 \mathrm{eV}$ related to $\mathrm{CaTiO}_{3}, \mathrm{CaCO}_{3}$ and hydroxyapatite, respectively $[2,3]$. The presence of $\mathrm{HA}$ is reinforced by the $\mathrm{P} 2 p$ spectrum peaked at $133.2 \mathrm{eV}$, corresponding to the binding energy of the $\mathrm{P}$ in hydroxyapatite [10]. Furthermore, the $\mathrm{O} 1 s$ peak at $531.9 \mathrm{eV}$ may also be ascribed to the presence of phosphate groups [3].

Figure $6 \mathrm{a}$ and $\mathrm{b}$ shows, respectively, images obtained by SEM from pristine and PIIID-coated titanium samples after immersion in SBF. As it can be noticed, the samples have different surface topographies. The film deposited by PIIID and the phosphate layer that resulted from the immersion in SBF may be responsible for the smoother surface observed in Figure 6b. In this picture the presence of small globules, which can also be indicative of the formation of calcium phosphates [3], can be also observed.

\section{Conclusion}

It has been observed that the exposure to Ca-containing plasmas enhanced the proportion of phosphorous and 
calcium on titanium surfaces after immersion in simulated body fluid. The results are compatible with the presence of such species on the surface as $\mathrm{CaTiO}_{3}, \mathrm{CaCO}_{3}$ and calcium phosphate, suggesting the formation of a hydroxyapatite layer on the metal. Therefore, the treatment performed is able to improve the titanium osteointegration.

The authors acknowledge the financial support of FAPESP (São Paulo State Research Foundation).

\section{References}

1. T. Hanawa, M. Ota, Biomaterials 12, 767 (1991)

2. X. Liu et al., Surf. Coat. Technol. 191, 43 (2005)
3. P.S. Vanzillota et al., Dent. Mater. 22, 275 (2006)

4. T.R. Rautray et al., J. Biomed. Mater. Res. B 93B, 581 (2010)

5. A. Andres, Handbook of Plasma Immersion Ion Implantation and Deposition (John Wiley and Sons, NY, 2000)

6. T. Kokubo, H. Takadama, Biomaterials 27, 2907 (2006)

7. R.M. Oliveira et al., IEEE Trans. Plasma Sci. 36, 2572 (2008)

8. W.B. White, The carbonate minerals, in The Infrared Spectra of Minerals, Monograph, vol. 4, edited by V.C. Farmer (Mineralogical Society, London, 1974), pp. $227-284$

9. T. Kizuki et al., Acta Biomater. 6, 2836 (2010)

10. M.T. Pham et al., J. Mater. Sci. Med. 11, 383 (2000) 